\title{
Staphylococcus aureus infections in Australasian neonatal nurseries
}

\author{
D Isaacs, S Fraser, G Hogg, H Y Li, for the Australasian Study Group for Neonatal Infections
}

Arch Dis Child Fetal Neonatal Ed 2004;89:F331-F335. doi: 10.1136/adc.2002.009480

See end of article for authors' affiliations

.....................

Correspondence to: Professor Isaacs,

Department of

Immunology and Infectious

Diseases, Children's

Hospital at Westmead,

Locked Bag 4001,

Westmead, NSW' 2145,

Australia; davidi@chw.

edu.au

Accepted 24 April 2003
Objective: To study the incidence and outcome of systemic infections with methicillin sensitive (MSSA) and methicillin resistant Staphylococcus aureus (MRSA) infections in Australasian neonatal nurseries.

Methods: Prospective longitudinal study of systemic infections (clinical sepsis plus positive cultures of blood and/or cerebrospinal fluid) in 17 Australasian neonatal nurseries.

Results: The incidence of early onset sepsis with S aureus, mainly MSSA, was 19 cases per 244718 live births or 0.08 per 1000. From 1992 to 1994, MRSA infections caused only 8\% of staphylococcal infections. From 1995 to 1998, there was an outbreak of MRSA infection, in two Melbourne hospitals. The outbreak resolved, after the use of topical mupirocin and improved handwashing. Babies with MRSA sepsis were significantly smaller than babies with MSSA sepsis (mean birth weight $1093 v 1617 \mathrm{~g}$ ) and more preterm (mean gestation $27.5 \vee 30.3$ weeks). The mortality of MRSA sepsis was $24.6 \%$ compared with $9.9 \%$ for MSSA infections. The mortality of early onset MSSA sepsis, however, was $39 \%$ (seven of 18) compared with $7.3 \%$ of late onset MSSA infection presenting more than two days after birth.

Conclusions: $S$ aureus is a rare but important cause of early onset sepsis. Late onset MRSA infections carried a higher mortality than late onset MSSA infections, but babies with early onset MSSA sepsis had a particularly high mortality.
O utbreaks of infection caused by Staphylococcus aureus have been described in neonatal nurseries since 1889, with large epidemics in the 1920s, 1950s, and early 1970 s. $^{12}$ The primary mode of transmission in neonatal nurseries is thought to be on the hands of staff, although $S$ aureus can also be carried in the nose and/or rectum of staff. ${ }^{2}$ Overcrowding of neonatal nurseries has been shown to be a major factor in spread to babies. ${ }^{3}$

Methicillin resistant strains of $S$ aureus (MRSA) have been an increasing problem in Australasian hospitals over the last 30 years, with infected and colonised patients the primary reservoirs of infection, and transmission mainly via hospital staff. $^{4-6}$ The incidence is highest in intensive care units. ${ }^{57}$ Topical mupirocin (pseudomonic acid) has been used to try to eradicate nasal and skin carriage of MRSA, although long term use is associated with the development of resistance, and recurrence is common after short term use. ${ }^{8}$ Other control measures that have been used successfully include improved handwashing and the cohorting of colonised babies. ${ }^{9} 10$

$S$ aureus is generally described as a nosocomial pathogen, and is rarely thought of as a cause of early onset neonatal sepsis. We previously reported $S$ aureus as the cause of two out of 100 cases of early onset sepsis in Australia. ${ }^{11} S$ aureus is, however, a vaginal commensal, and thus a potential early onset pathogen.

\section{METHODS}

The Australasian Study Group for Neonatal Infections is a group of neonatal clinicians in Australia and New Zealand, who have been collecting prospective data on neonatal infections since October 1991. Initially the group comprised seven neonatal units, but now includes 17 in Australia and New Zealand, of which 11 are attached to maternity hospitals and able to provide data on the annual number of live births. Since 1992, data have been recorded from 29 000-44 000 live births annually, representing $11-18 \%$ of all annual live births in Australia.
Babies who fulfil the study definition of sepsis are reported on a standard questionnaire, recording the baby's initials but no other identifying data, the birth weight, gestational age, race, time of first positive culture, organism, sensitivities, and results of blood and cerebrospinal fluid (CSF) cultures. Participants are asked to report associated infections, such as pneumonia or skin sepsis. The only outcome recorded is survival. Institutional bioethics committee approval was obtained to collect the data.

Neonatal sepsis is defined as a baby with clinical sepsis and pure growth of a single organism from blood or CSF. When the organism is a possible contaminant, the clinician is asked only to report babies with clinical sepsis and in whom there is also at least one abnormal haematological test (abnormally high or low peripheral white blood cell count, abnormal immature to total white cell ratio using the reference ranges of Manroe, ${ }^{12}$ or thrombocytopenia). Blood cultures growing more than one organism are considered to be contaminants.

Early onset sepsis is defined as sepsis occurring in the first 48 hours after delivery, and late onset sepsis as that occurring after 48 hours. Meningitis is defined as a clinical picture consistent with meningitis, and either a positive CSF culture or raised CSF white cell count $\left(>100 \times 10^{6} / 1\right)$. Strains of $S$ aureus were identified, and sensitivities determined locally using standard microbiological methods. Because of the size and severity of the outbreak of MRSA infection in Melbourne, 25 of the strains causing MRSA sepsis in babies from hospitals A and B over the years 1995-1998 (15 from 1995, two from 1996, and eight from 1997) were studied at the Microbiology Diagnostic Unit by pulsed field gel electrophoresis.

Abbreviations: CSF, cerebrospinal fluid; MRSA, methicillin resistant Staphylococcus aureus; MSSA, methicillin sensitive Staphylococcus aureus 
Rates of MRSA were not specifically recorded in other areas within maternity hospitals outside the neonatal area, but it is known from other studies that MRSA is common in adult hospitals in Australia. ${ }^{6}$ We did not routinely collect data about MRSA colonisation.

Statistical analysis was by $t, \chi^{2}$, and Fisher's exact test.

\section{RESULTS}

From 1992 to 1994 inclusive, only seven of 93 (8\%) cases of $S$ aureus sepsis were due to MRSA. These occurred in hospitals in Melbourne and Sydney (fig 1). Between 1995 and 1998, the proportion of MRSA cases rose to $34.3 \%$, comprising 58 of a total of 169 cases. Most MRSA infections occurred in Melbourne, in either hospital A (4l cases) or hospital B (nine cases), to which babies from hospital A were often transferred. In 1999, however, there were 26 cases of $S$ aureus sepsis in Australasia, and all 26 were due to methicillin sensitive strains (MSSA).
The mortality from MRSA was high, particularly in 19951996, when it was 39\% for children in hospital A ( 10 of 26) and hospital B (two of five). The MRSA outbreak appeared to resolve, but then returned, although none of the 15 babies infected in 1997-1998 died. Analysis, by pulsed field gel electrophoresis, of 25 of 28 of the MRSA strains from hospitals A and B showed that 23 of the 25 infections throughout the time of the outbreak were caused by a common strain (fig 2). The two MRSA strains that were genetically different from the epidemic MRSA strain both came from hospital A in 1995. Hospital A instituted the use of topical mupirocin to colonised babies, and improved handwashing, but cohorting of babies was not possible.

The overall mortality from MRSA throughout the study period was 16 of 65 babies $(24.6 \%)$, significantly higher than for MSSA sepsis, which was 22 of 223 (9.9\%) $(\mathrm{p}<0.001)$.

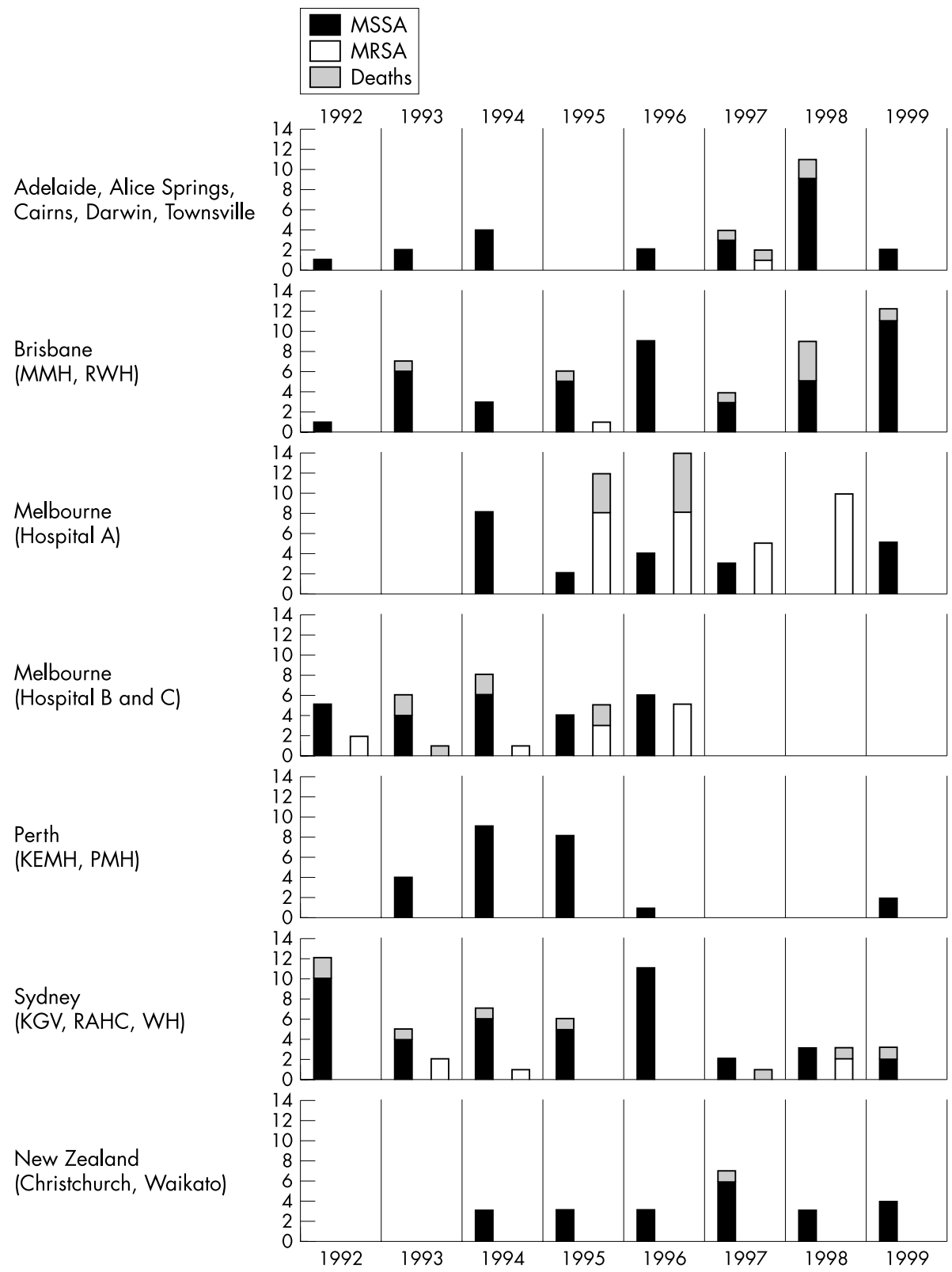

Figure 1 Local incidence and mortality of systemic infections due to Staphylococcus aureus which are methicillin sensitive (MSSA) or methicillin resistant (MRSA). Hospitals A, B, and C are three different Melbourne hospitals. 


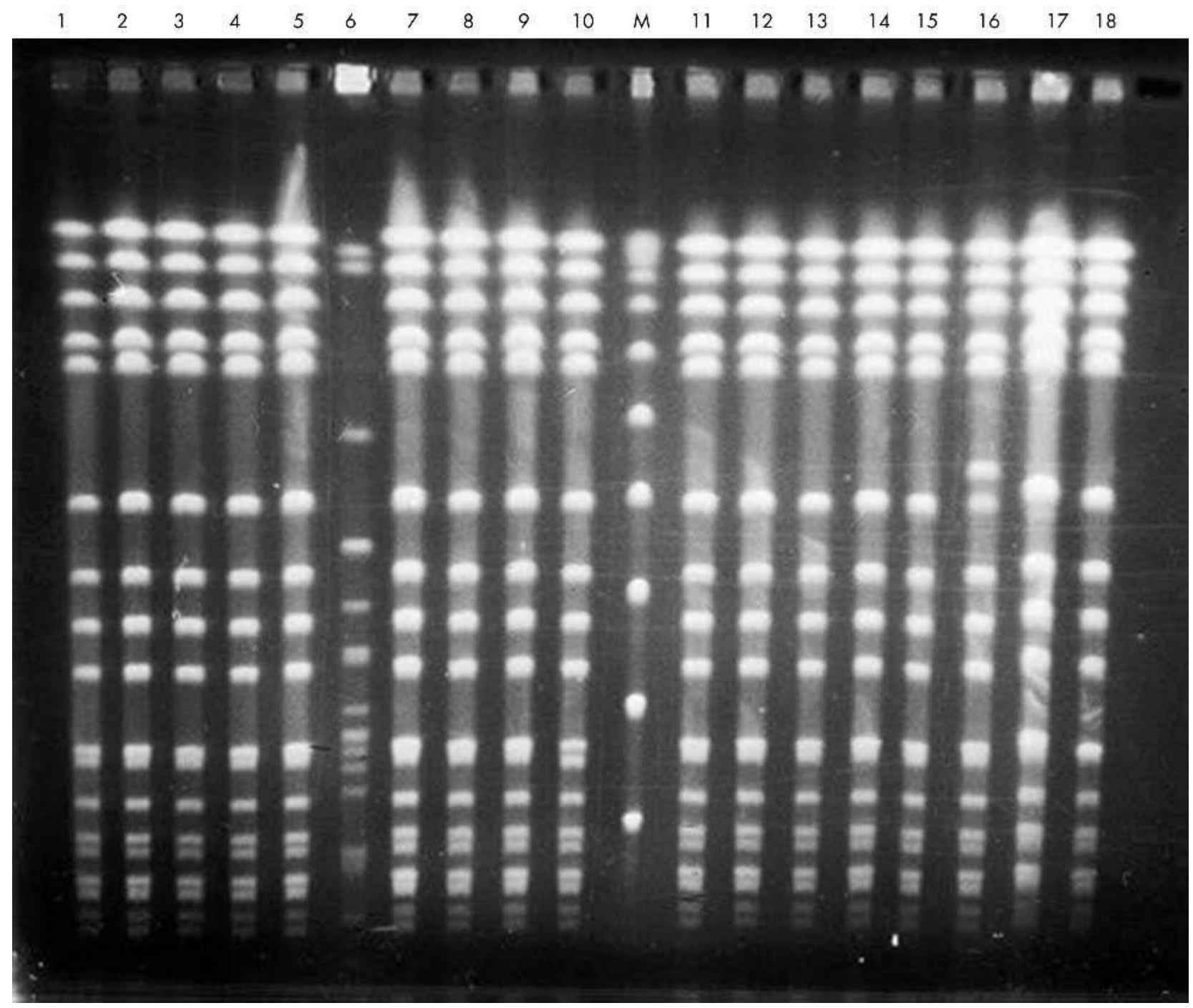

Figure 2 Pulsed field gel electrophoresis of strains of methicillin resistant Staphylococcus aureus (MRSA). DNA from 18 MRSA isolates digested with Smal and separated at $6 \mathrm{~V} / \mathrm{cm}$ for 22 hours with a switch time of 5-25 seconds. Lane marked M, Lambda DNA ladder. Isolates 1-5, 7-15, 17 and 18 showed identical patterns.

Table 1 reports the infections associated with $S$ aureus sepsis. Skin abscesses or cellulitis were more likely to occur

\begin{tabular}{|c|c|c|c|}
\hline & $\begin{array}{l}\text { Methicillin } \\
\text { sensitive ( } n=223 \text { ) }\end{array}$ & $\begin{array}{l}\text { Methicillin } \\
\text { resistant (n=65) }\end{array}$ & p Value \\
\hline $\begin{array}{l}\text { Skin abscesses or } \\
\text { cellulitis }\end{array}$ & $19(8.5)$ & $17(26)$ & $<0.05$ \\
\hline $\begin{array}{l}\text { Osteomyelitis and/or } \\
\text { septic arthritis }\end{array}$ & $19(8.5)$ & 0 & $<0.05$ \\
\hline Pneumonia & $9(4.0)$ & $8(12)$ & NS \\
\hline Meningitis & $5(2.2)$ & $3(5)$ & NS \\
\hline Urinary tract infection & $5(2.2)$ & 0 & NS \\
\hline Omphalitis & $4(1.8)$ & 0 & NS \\
\hline Endocarditis & $3(1.3)$ & $1(2)$ & NS \\
\hline Wound infection & $3(1.3)$ & $3(5)$ & NS \\
\hline $\begin{array}{l}\text { Necrotising } \\
\text { enterocolitis }\end{array}$ & $3(1.3)$ & $3(5)$ & NS \\
\hline Thrombophlebitis & $1(0.4)$ & $2(3)$ & NS \\
\hline Patent urachus & $1(0.4)$ & 0 & NS \\
\hline Deep organ abscess & 0 & $1(2)$ & NS \\
\hline
\end{tabular}

with MRSA, whereas osteomyelitis and/or septic arthritis were only reported in association with MSSA infections.

Babies with MRSA sepsis were born significantly more preterm than babies with MSSA sepsis (mean (SD) gestational age at birth 27.5 (3.9) $v 30.3$ (5.7) weeks, p $<0.001$ ) and weighed significantly less (mean (SD) birth weight 1093 (795) $v 1617$ (1149) g, p < 0.001). The mean (SD) age at first positive culture was identical: 17.9 (18.8) days for MSSA sepsis and 17.9 (19.3) days for MRSA sepsis. However, only one of 65 babies with MRSA sepsis had early onset sepsis (the culture was positive on day 2), compared with 18 of 223 babies with MSSA sepsis ( $p<0.05), 12$ on day one, and six on day two. The mortality of early onset MSSA sepsis was $39 \%$ : five of the 12 babies with positive day one cultures and two of the six with positive day two cultures. In contrast, 15 of 205 babies $(7.3 \%)$ with late onset MSSA sepsis died $(\mathrm{p}<0.01)$.

The overall incidence of early onset $S$ aureus infection was calculated from the number of babies born in maternity hospitals who developed infection on day one or two divided by the number of live births in those hospitals over the whole study period: 19 cases in 244718 live births or 0.08 per 1000 live births. 


\section{DISCUSSION}

MRSA has become a worldwide problem over the last 30 years, particularly in intensive care units, including neonatal units. ${ }^{12-20}$ The genes for methicillin resistance code for a penicillin binding protein that is less susceptible to the action of $\beta$ lactam antibiotics on cell wall synthesis. They are usually chromosomally rather than plasmid mediated. The gene appears to render the cell wall and thus the organism more stable. $^{21}$

There are many strains of MRSA, which can vary in their virulence. In a Japanese study, MRSA strains of coagulase type II were associated with a higher mortality than other strains. ${ }^{22}$ On the other hand, a French study of cancer patients found that MRSA patients remained bacteraemic longer than MSSA patients, but there was no difference in survival or length of hospital stay. ${ }^{23}$

There are surprisingly few data on either the clinical manifestations or outcome of neonatal MRSA infection. In our study MRSA infection affected babies who were smaller and born more premature, and was associated with a greater mortality than MSSA infection. Because MRSA predominantly occurred in one neonatal unit (41 of the 65 cases), it is possible that there is a bias towards smaller babies being looked after in that unit. However, babies in the same unit with MSSA sepsis were not significantly different from other babies in the study with MSSA sepsis. It is also possible that the increased mortality from MRSA sepsis is attributable to the babies being more preterm, rather than increased virulence of the organism per se. The mortality from MRSA sepsis at hospital A fell from 1995 to 1998, despite there being no detectable genetic change in the infecting strain of MRSA. The reason may have been increased awareness and vigilance, or an undetectable change in the organism's virulence.

The clinical manifestations of MRSA and MSSA differed in some important respects. MRSA was more often associated with skin sepsis, an observation made previously. ${ }^{17}$ MSSA was associated with bone and joint infection, but not MRSA. In a previous report from Westmead Hospital, Sydney, one of the hospitals contributing data to our study, the authors reported 20 cases of MRSA osteomyelitis or septic arthritis in their tertiary neonatal unit over six years. ${ }^{24}$ They do not comment on MSSA osteomyelitis over the same period. However, Wong et $a^{25}$ reported that 16 of 30 babies with neonatal osteomyelitis had MSSA infection, and only seven had MRSA, while Storch and Rajugopalan ${ }^{26}$ found that MSSA was significantly more likely to cause bone and joint infection, which occurred in only one of seven babies with MRSA sepsis.

Early onset neonatal sepsis due to $S$ aureus is rare, but is certainly described. In an earlier report from this study group, two babies with $S$ aureus infection among 100 with early onset sepsis were described. ${ }^{11} S$ aureus is a skin commensal and thus its growth from blood cultures can represent contamination rather than true sepsis. On the other hand, the high mortality associated with early onset $S$ aureus infection in this report suggests that most if not all cases were genuine infections. The reported incidence of early onset neonatal infection with $S$ aureus will also depend on the definition of early onset used. Stoll et al ${ }^{27}$ defined it as "within the first 72 hours of life" and reported $S$ aureus as the cause of four of 147 episodes of early onset sepsis in very low birthweight $(<1500 \mathrm{~g})$ babies. We found that early onset $S$ aureus infection $<48$ hours old occurred at an incidence of 0.08 per 1000 live births, which means that a hospital delivering 5000 babies per year could expect to see one case every 30 months. This is probably not common enough to warrant a change in empiric antibiotic therapy for early onset sepsis to improve anti-staphylococcal cover, but it does necessitate vigilance, and implies that the isolation of $S$ aureus from a maternal vaginal swab should not be ignored. If we had used the definition of Stoll et al of early onset sepsis as $<72$ hours old, we would have identified an extra eight babies (seven MSSA, one MRSA), and the incidence would have been 0.11 per 1000 live births.

This study was not designed to look specifically at control of MRSA infections, and, although the disappearance of MRSA from hospital A was attributed by its staff to use of topical mupirocin and improved handwashing, we had no data to verify this observation. The antibiotic prescribing policy was changed in hospitals A and B to empirical use of vancomycin for late onset sepsis after the emergence of MRSA as a major pathogen, but not previously. These hospitals have central line policies that are standard in Australasia, and were no different from those in other hospitals. Hospitals A and B did not look after a population of babies that differed significantly from other hospitals. Control of MRSA in neonatal units is often difficult. Back et $a l^{28}$ found that five days of topical mupirocin to babies and staff did not eradicate MRSA colonisation, but spread ceased, only to recur four months later, a situation not dissimilar to that at hospital A. The recurrence stopped after cohorting babies who were found by intensive surveillance cultures to be colonised. Zafar et $a^{29}$ reported that aggressive infection control measures were ineffective in halting an MRSA outbreak until the handwashing, and bathing soap was changed to $0.3 \%$ triclosan. Others have reported that cohorting or improved handwashing alone have been sufficient to end outbreaks. ${ }^{8-10}$ Our surveillance data suggest that MRSA infections, although they have a high mortality when they occur, are an uncommon problem in Australasian neonatal units, despite a very high incidence of MRSA in adult and paediatric Australasian hospitals..$^{4-7}{ }^{20}$ This suggests that control of such infections is possible through good infection control practices.

\section{ACKNOWLEDGEMENTS}

Thanks to many colleagues for data collection, including particularly, Andrew Daley, Mary Poynten, David McIntosh, Michael Nissen, Melanie Wong, Janelle Meyers, Kate Panaretto, and Anne Arthur. Australasian Study Group for Neonatal Infections: C Barfield, MB, FRACP (Monash Medical Centre, Melbourne, Australia); D Bouchier, MB, FRACP (Waikato, New Zealand); I Bucens, MB, FRACP; A Ruben, MB, FRACP (Royal Darwin Hospital, Darwin, Australia); D Cartwright, MB, FRACP (Royal Women's Hospital, Brisbane, Australia); T Clothier, MBBS; J Ehrlich, MB, FRACP; F Morey, PhD (Alice Springs Hospital, Alice Springs, Australia); B Darlow, MB, FRACP (Christchurch, New Zealand); S Fraser, MB, FRACP (Mercy Hospital, Melbourne, Australia); L Gilbert, MD, FRACP (Westmead Hospital, Westmead, Australia); K Grimwood, MD, FRACP; P McDougall, MD, FRACP; J Royle, MB, FRACP (Royal Children's Hospital, Melbourne, Australia); D Henderson-Smart, MD, FRACP; H Jeffery, MD, FRACP (King George V Hospital, Sydney, Australia); D Isaacs, MD, FRACP; J Peat, PhD (statistician) (Royal Alexandra Hospital for Children, Sydney); R Kohan, MB, FRACP (King Edward Memorial Hospital, Perth, Australia); A McPhee, MB, FRACP (Women's and Children's Hospital, Adelaide, Australia); R Messer, MB, FRACP (Cairns Base Hospital, Cairns, Australia); C Minutillo, MD, FRACP (Princess Margaret Hospital, Perth, Australia); D Tudehope, MD, FRACP (Mater Hospital, Brisbane, Australia); J Whitehall MB, FRACP (Kirwan Hospital, Townsville).

\section{Authors' affiliations}

D Isaacs, Children's Hospital at Westmead, Westmead, NSW 2145, Australia

S Fraser, Mercy Hospital for Women, Clarendon Street, East Melbourne, VIC 3002, Australia

G Hogg, H Y Li, Microbiology Diagnostic Unit, University of Melbourne, Parkville, VIC 3052, Australia 


\section{REFERENCES}

1 Kilham EB. An epidemic of pemphigus neonatorum. Am J Obstet 1989;22:1039.

2 Shinefield HR. Staphylococcal infections. In: Remington JS, Klein JO, eds. Infectious diseases of the fetus and newborn infant, 4th ed. Philadelphia: WB Saunders, 1995: 1105-41.

3 Haley RW, Bregman DA. The role of understaffing and overcrowding in recurrent outbreaks of staphylococcal infection in a neonatal intensive care unit. J Infect Dis 1982;145:875-85.

4 McDonald M. The epidemiology of methicillin-resistant Staphylococcus aureus: surgical relevance 20 years on. Aust N Z J Surg 1997;67:682-5.

5 Givney R, Vickery A, Holliday A, et al. Evolution of an endemic methicillinresistant Staphylococcus aureus population in an Australian hospital from 1967 to 1996. J Clin Microbiol 1998;36:552-6.

6 Gottlieb T, Mitchell D. The independent evolution of resistance to ciprofloxacin, rifampicin, and fusidic acid in methicillin-resistant Staphylococcus aureus in Australian teaching hospitals (1990-1995) Australian Group for Antimicrobial Resistance (AGAR). J Antimicrob Chemother 1998;42:67-73.

7 Barakate MS, Yang YX, Foo SH, et al. An epidemiological survey of methicillin-resistant Staphylococcus aureus in a tertiary referral hospital. $J$ Hosp Infect 2000;44:19-26.

8 Davies EA, Emmerson AM, Hogg GM, et al. An outbreak of infection with a methicillin-resistant Staphylococcus aureus in a special care baby unit. $J$ Hosp Infect 1987; 10:120-8.

9 Millar MR, Keyworth N, Lincoln C, et al. 'Methicillin-resistant' Staphylococcus aureus in a regional neonatology unit. J Hosp Infect 1987;10:187-97.

10 Haley RW, Cushion NB, Tenover FC, et al. Eradication of endemic methicillin resistant Staphylococcus aureus infections from a neonatal intensive care unit. $J$ Infect Dis 1995;171:614-24.

11 Isaacs D, Barfield C, Grimwood K, et al. Systemic bacterial and fungal infections in infants in Australian neonatal units. Med J Aust 1995; 162:198-201.

12 Morgan M, Salmon R, Evans-Williams D et al. Resistance to methicillin in isolates of Staphylococcus aureus from blood and cerebrospinal fluid in Wales, 1993-1997. J Antimicrob Chemother 1999;44:541-4.

13 Mitsuda T, Arai K, Ibe $M$, et al. The influence of methicillin-resistant Staphylococcus aureus (MRSA) carriers in a nursery and transmission of MRSA to their households. J Hosp Infect 1999:42:45-51.

14 Johnson Z, Fitzpatrick P, Hayes C, et al. National survey of MRSA: Ireland, $1995 \mathrm{~J}$ Hosp Infect 1997;35:175-84.

15 Jernigan TA, Titus MG, Groschel DH, et al. Effectiveness of contact isolation during a hospital outbreak of methicillin-resistant Staphylococcus aureus. Am J Epidemiol 1996;143:496-504.
16 Tan KW, Tay L, Lim SH. An outbreak of methicillin-resistant Staphylococcus aureus in a neonatal intensive care unit in Singapore: a 20 month study of clinical characteristics and control. Singapore Med J 1994;35:277-82.

17 Cheong I, Tan SC, Wong YH, et al. Methicillin-resistant Staphylococcus aureus (MRSA) in a Malaysian hospital. Med J Malaysia 1994;49:24-8

18 Liv CC, Hor LI, Wu YH, et al. Investigation and elimination of epidemic methicillin-resistant Staphylococcus aureus in a neonatal intensive care unit. Zhonghua Min Guo Xiao Er Ke Yi Xue Hui Za Zhi 1993;34:285-93.

19 Haddad Q, Sobayo El, Basit OB, et al. Outbreak of methicillin-resistant Staphylococcus aureus in a neonatal intensive care unit. J Hosp Infect 1993;23:211-22

20 Heffernan H, Stehr-Green J, Davies H, et al. Methicillin resistant Staphylococcus aureus (MRSA) in New Zealand 1988-90. N Z Med J 1993;106:72-4.

21 Editorial. What's to be done about resistant staphylococci? Lancet 1985;ii: 189-90.

22 Nada T, Ichiyama S, linuma $Y$, et al. Types of methicillin-resistant Staphylococcus aureus associated with high mortality in patients with bacteremia. Eur J Clin Microbiol Infect Dis 1996;15:340-3.

23 Marty L, Flahault A, Suarez B, et al. Resistance to methicillin and virulence of Staphylococcus aureus strains in bacteriemic cancer patients. Intens Care Med 1993;19:285-9.

24 Ish-Horowicz MR, Mclntyre P, Nade S. Bone and joint infections caused by multiply resistant Staphylococcus aureus in a neonatal intensive care unit. Pediatr Infect Dis J 1992;11:82-7.

25 Wong $M$, Isaacs $D$, Howman-Giles $R$, et al. Clinical and diagnostic features of osteomyelitis occurring in the first three months of life. Pediatr Infect Dis $J$ 1995; 14:1047-53.

26 Storch GA, Rajugopalan L. Methicillin-resistant Staphylococcus aureus bacteremia in children. Pediatr Infect Dis 1986;5:59-67.

27 Stoll BJ, Gordon T, Korones SB, et al. Early-onset sepsis in very low birth weight neonates: a report from the National Institute of Child Health and Human Development Neonatal Research Network. J Pediatr 1996; 129:72-80.

28 Back NA, Linnemann CC Jr, Staneck JL, et al. Control of methicillin-resistant Staphylococcus aureus in a neonatal intensive-care unit: use of intensive microbiologic surveillance and mupirocin. Infect Control Hosp Epidemiol 1996; 17:227-31.

29 Zafar AB, Butler RC, Reese DJ, et al. Use of $0.3 \%$ triclosan (Bacti-Stat) to eradicate an outbreak of methicillin-resistant Staphylococcus aureus in a neonatal nursery. Am J Infect Control 1995;23:200-8. 